\title{
Tissue Distribution of Menaquinone-7 and the Effect of $\alpha$-Tocopherol Intake on Menaquinone-7 Concentration in Rats
}

\author{
Saiko IKEDA ${ }^{1}$, Fumiaki HANZAWA ${ }^{1}$, Saki TAKAHASHI ${ }^{1}$, Norie SuZUKI $^{1}$, \\ Kana $\mathrm{SANO}^{1}$, Hiroaki ODA ${ }^{2}$ and Tomono UCHIDA ${ }^{3}$ \\ ${ }^{1}$ Department of Nutritional Sciences, Nagoya University of Arts and Sciences, Nisshin 470-0196, Japan \\ ${ }^{2}$ Graduate School of Bioagricultural Sciences, Nagoya University, Nagoya 464-8601, Japan \\ ${ }^{3}$ Department of Home Economics, Aichi Gakusen University, Okazaki 444-8520, Japan
}

(Received May 10, 2018)

\begin{abstract}
Summary We have reported that vitamin E intake lowers phylloquinone (PK) concentration in extrahepatic tissues of rats. In this study, we aimed to clarify the characteristic of the distribution of menaquinone-7 (MK-7), a vitamin K contained in fermented foods, by comparison with other vitamin $\mathrm{K}$ distributions and to clarify the effect of vitamin $\mathrm{E}$ intake on MK-7 concentration in rats. Rats were fed a vitamin K-free diet (Free group), a diet containing $0.75 \mathrm{mg} \mathrm{PK} / \mathrm{kg}$ (PK group), a $0.74 \mathrm{mg}$ menaquinone-4 (MK-4)/kg diet (MK-4 group), a $1.08 \mathrm{mg}$ MK-7/kg diet (MK-7 group), or a $0.29 \mathrm{mg}$ menadione (MD) $/ \mathrm{kg} \operatorname{diet}$ (MD group) for 16 wk. MK-7 mainly accumulated in the liver, spleen, and adrenal gland of the MK-7 group, although PK accumulated in the serum and all tissues of the PK group. Conversely, MK-4 was present in all tissues of the PK, MK-4, MK-7, and MD groups. MK-4 concentration in the serum, liver, adipose tissue, and spleen was higher in the MK-4 group than in the other groups; however, MK-4 concentration in the kidney, testis, tibia, and brain was lower in the MK-4 group than in the PK, MK-7, and MD groups. Next, vitamin E- and K-deficient rats were orally administered MK-7 with or without $\alpha$-tocopherol. $\alpha$-Tocopherol did not affect MK-7 or MK-4 concentration in the serum and various tissues. These results suggested that MK-7 is particularly liable to accumulate in the liver, and MK-7 concentration is not affected by vitamin $\mathrm{E}$ intake.
\end{abstract}

Key Words menaquinone-4, menaquinone-7 distribution, phylloquinone, vitamin E, vitamin K metabolism

Vitamin $\mathrm{K}$ is classified into three forms: phylloquinone (PK), which is vitamin $\mathrm{K}_{1}$, menaquinone, which is vitamin $\mathrm{K}_{2}$, and menadione (MD), which is vitamin $\mathrm{K}_{3}$. Approximately ten types of menaquinone exist, depending on the length of the side chain. Among them, vitamin $\mathrm{K}$ is mostly consumed from the Japanese diet in the form of PK, and the main source of PK is green vegetables. The vitamin $\mathrm{K}$ that is second most abundant in the Japanese diet is menaquinone-7 (MK-7) (1). The main source of MK-7 is fermented foods such as natto and cheese. Menaquinone-4 (MK-4) is contained in meat and eggs in small amounts, and is biosynthesized from PK and MD in the body (2-5). Menaquinones are also produced by microbiota in the intestine $(6,7)$. MD is produced from PK in the body $(8)$ and is also used as a synthetic vitamin $\mathrm{K}$ for some experimental diets of animal studies (9). In the Dietary Reference Intake for Japanese 2015, the total intake of PK, MK-4, and MK-7 is taken as vitamin $\mathrm{K}$ intake.

Because a large amount of MK-7 is contained in natto, a traditional Japanese fermented food, the MK-7

E-mail: saiko@nuas.ac.jp

Abbreviations: MD, menadione; MK-3, menaquinone-3; MK-4, menaquinone-4; MK-7, menaquinone-7; PK, phylloquinone. intake of some Japanese who ingest natto habitually is high (1). Recently, several studies have reported on the effect of MK-7 on maturation of bone protein, bone structure, vascular calcification and stiffness, and symptoms of rheumatoid arthritis in humans (10-14). With the expectation of these useful effects, MK-7 is also used as a supplement (15). However, details about tissue distribution of MK-7 and its metabolism are still limited. Therefore, in the present study, we aimed to clarify the characteristics of tissue distribution of MK-7 by comparison of vitamin $\mathrm{K}$ concentration in the tissues of rats fed a diet containing PK, MK-4, MK-7, or MD, which are commercially available as reagents.

Among the vitamin $\mathrm{K}$ types, $\mathrm{PK}$ is added to the AIN93-rodent diet (16), which is widely used in animal experiments as a standard rodent diet. We have revealed that PK concentration in the extrahepatic tissues of rats fed the AIN93-rodent diet decreases as the vitamin E content in the diet increases (17). Consumption of a diet containing a $75 \mathrm{IU} \alpha$-tocopherol $/ \mathrm{kg}$ diet, a basal content of vitamin E in the AIN93-rodent diet, significantly lowered PK concentration in the various tissues except for the liver of rats, although consumption of a diet containing an excess amount of $\gamma$-tocopherol lowered PK concentration in some tissues. However, in the tissues of rats fed PK, vitamin E intake had little effect on 
concentration of MK-4 converted from PK in the body. Vitamin E intake did not affect MK-4 concentration in the tissues of rats fed a diet containing MK-4 as vitamin $\mathrm{K}$ instead of PK. In addition, vitamin $\mathrm{E}$ intake did not affect uncarboxylated-osteocalcin concentration in the serum, bone density of the femur, or expression of the gene related to bone formation and resorption in the femur of rats in which the PK concentration of the bone decreased less than $60 \%$ with excess intake of vitamin $\mathrm{E}$ (18). It has been suggested that MK-4 is synthesized by conversion from PK and contributes to the physiological action of vitamin K (19). Therefore, although vitamin E intake lowers extrahepatic PK concentration, it is unlikely to affect the physiological action of vitamin K. MK-7 is common as food-derived vitamin $\mathrm{K}$ for Japanese as mentioned above. MK-7 is also a precursor of MK-4, and is converted into MK-4 in the body like PK, suggesting that MK-7 concentration may be affected by vitamin E intake. Therefore, the effect of $\alpha$-tocopherol on MK-7 and MK- 4 concentrations in tissues after MK-7 administration was examined in the present study.

\section{MATERIALS AND METHODS}

Materials and animals. PK, MK-4, MK-7, and MD were purchased from Sigma-Aldrich Japan (Tokyo, Japan). Menaquinone-3 (MK-3) used as an internal standard for vitamin $\mathrm{K}$ determination and $R R R-\alpha$ tocopherol used for oral administration were generously donated by Eisai Co., Ltd. (Tokyo, Japan) and MitsubishiChemical Foods Corporation (Tokyo, Japan), respectively.

Specific pathogen-free male Wistar rats were purchased from Japan SLC, Inc. (Shizuoka, Japan), housed in individual wire-bottomed cages, maintained in a temperature- and humidity-controlled clean room with a 12-light/dark cycle (lights on from 0800 to $2000 \mathrm{~h}$ ), and allowed access to water ad libitum throughout. The study was approved by the Laboratory Animal Care Committee of Nagoya University of Arts and Sciences (approval numbers 72 and 80) and all procedures were performed in accordance with the Animal Experimentation Guidelines of Nagoya University of Arts and Sciences.

Examination of dietary $P K, M K-4, M K-7$, or $M D$ on vitamin $K$ concentrations (experiment 1 ). Four-wk-old rats were fed a vitamin K-free diet (Free group, $n=6$ ), a diet containing $0.75 \mathrm{mg} \mathrm{PK} / \mathrm{kg}$ (PK group, $n=6$ ), a $0.74 \mathrm{mg} \mathrm{MK}-4 / \mathrm{kg} \operatorname{diet}(\mathrm{MK}-4$ group, $n=6$ ), a $1.08 \mathrm{mg}$ MK-7/kg diet (MK-7 group, $n=6$ ), or a $0.29 \mathrm{mg} \mathrm{MD/}$ $\mathrm{kg}$ diet (MD group, $n=6$ ) for $16 \mathrm{wk}$. Vitamin K content in the diets was adjusted so that the molar content of vitamin $\mathrm{K}$ was equal. The composition of the diets based on the AIN93-rodent diet (16) was (in $\mathrm{g} / \mathrm{kg}$ ) casein, 200; L-cystine, 3; cornstarch, 529.5; sucrose, 100; cellulose powder, 50; mineral mixture (16), 35; vitamin K-free vitamin mixture (16), 10; choline bitartrate, 2.5; and stripped corn oil (Funabashi Farm Co., Ltd.), 70. Stripped corn oil contained a negligible amount of vitamin E and K. The diets were freshly prepared, protected from light, stored at $-30^{\circ} \mathrm{C}$, and used within $1 \mathrm{wk}$. Rats had free access to food and were killed by decapitation.
The serum, liver, perirenal adipose tissue, heart, spleen, muscle, lung, adrenal gland, kidney, testis, brain, and tibia were taken and stored at $-30^{\circ} \mathrm{C}$ until subjected to vitamin $\mathrm{K}$ determination.

Examination of orally administered vitamin $E$ effects on MK-7 and MK-4 concentrations (experiment 2). Threewk-old rats were fed a vitamin E- and K-free diet for 3 mo to deplete their vitamin $\mathrm{E}$ and $\mathrm{K}$ stores. Then, the rats were administered by gavage $1 \mathrm{~mL}$ of an emulsion containing $0.2 \mathrm{mg}$ PK (PK group, $n=7$ or 8 ), $0.29 \mathrm{mg}$ MK-7 (MK-7 group, $n=7$ or 8 ), or $0.29 \mathrm{mg} \mathrm{MK-7} \mathrm{with}$ $10 \mathrm{mg} R R R$ - $\alpha$-tocopherol (MK-7E group, $n=7$ or 8 ). The vitamin $\mathrm{K}$ content in the emulsion was adjusted so that the number of moles was equal. To facilitate fat-soluble vitamin absorption, all emulsion, prepared immediately before use, contained $200 \mathrm{mg}$ of sodium taurocholate, $200 \mathrm{mg}$ of triolein, $50 \mathrm{mg}$ of albumin, and water. The rats were deprived of food for $12 \mathrm{~h}$ until oral administration of the emulsion. At 0,6 , or $24 \mathrm{~h}$ after the oral administration, rats were killed by decapitation. The serum, liver, heart, spleen, lung, kidney, adrenal gland, testis, and brain were taken and stored at $-30^{\circ} \mathrm{C}$ until being subjected to vitamin $\mathrm{K}$ determination.

Measurement of vitamin $K$ and $E$ concentrations. Vitamin K (PK, MK-4, and MK-7) and $\alpha$-tocopherol concentrations in serum and tissues were determined by HPLC with a fluorescence detector as previously described (20, 21).

Statistical analysis. Data are presented as the means \pm SE. Data were analyzed by one-way ANOVA followed by Tukey's post-hoc test. Differences were regarded as significant at $p<0.05$. All data were analyzed using GraphPad Prism 6 for Windows (GraphPad Software, San Diego, CA).

\section{RESULTS}

Effect of dietary PK, MK-4, MK-7, or MD on vitamin $K$ concentrations (experiment 1)

Initial body weights $(\mathrm{g})$ of the Free, PK, MK-4, MK-7, and MD groups were $61.7 \pm 1.2,61.6 \pm 1.1,61.6 \pm 1.0$, $61.6 \pm 1.0$, and $61.6 \pm 1.0$, respectively. Final body weights $(\mathrm{g})$ of the Free, PK, MK-4, MK-7, and MD groups were $359 \pm 3,359 \pm 11,358 \pm 11,367 \pm 12$, and $376 \pm 8$, respectively. Relative liver weights $(\mathrm{g} / \mathrm{kg}$ body weight) of the Free, PK, MK-4, MK-7, and MD groups were $33.0 \pm 0.7,31.7 \pm 1.0,30.3 \pm 0.7,32.2 \pm 0.4$, and $31.6 \pm 0.6$, respectively. Thus, differences of vitamin $\mathrm{K}$ in the diets did not affect the growth or liver weight of rats.

PK accumulated in the serum and all tissues of the PK group, and its concentration in the serum and all tissues of the other groups was extremely low or undetectable (Table 1). The high concentrations of PK $(>100 \mathrm{pmol} / \mathrm{g})$ were in the adipose tissue, adrenal gland, liver, spleen, and heart of the PK group.

MK-7 accumulated mainly $(>100 \mathrm{pmol} / \mathrm{g})$ in the liver, adrenal gland, and spleen of the MK-7 group. In particular, the MK-7 concentration in the liver was as high as $801 \pm 57 \mathrm{pmol} / \mathrm{g}$. However, MK-7 in the adipose tissue, heart, muscle, lung, testis, and brain of the 
Table 1. PK, MK-4, and MK-7 concentrations in serum and tissues in experiment 1.

\begin{tabular}{|c|c|c|c|c|c|}
\hline & Free & PK & MK-4 & MK-7 & $\mathrm{MD}$ \\
\hline \multicolumn{6}{|l|}{ Serum } \\
\hline PK & nd & $12.3 \pm 3.2$ & nd & nd & nd \\
\hline MK-4 & nd & nd & $4.02 \pm 0.31$ & nd & nd \\
\hline \multicolumn{6}{|l|}{ Liver } \\
\hline PK & nd & $296 \pm 16$ & nd & nd & nd \\
\hline MK-4 & $0.438 \pm 0.284^{\mathrm{c}}$ & $0.900 \pm 0.343^{b c}$ & $18.1 \pm 0.9^{a}$ & $2.55 \pm 0.36^{b c}$ & $4.08 \pm 1.39^{b}$ \\
\hline MK-7 & nd & nd & nd & $801 \pm 57^{\mathrm{a}}$ & nd \\
\hline \multicolumn{6}{|c|}{ Perirenal adipose tissue } \\
\hline PK & nd & $459 \pm 45$ & nd & nd & nd \\
\hline MK-4 & nd & $112 \pm 23^{b}$ & $522 \pm 36^{\mathrm{a}}$ & $96.0 \pm 17.8^{b}$ & $139 \pm 14^{b}$ \\
\hline \multicolumn{6}{|l|}{ Heart } \\
\hline PK & nd & $106 \pm 7$ & nd & nd & nd \\
\hline MK-4 & $8.21 \pm 0.71^{\mathrm{c}}$ & $20.4 \pm 2.1^{\mathrm{ab}}$ & $29.6 \pm 4.7^{\mathrm{a}}$ & $18.1 \pm 1.3^{\mathrm{bc}}$ & $25.4 \pm 1.8^{\mathrm{ab}}$ \\
\hline \multicolumn{6}{|l|}{ Spleen } \\
\hline PK & nd & $118 \pm 14^{\mathrm{a}}$ & nd & nd & $3.53 \pm 2.07^{\mathrm{b}}$ \\
\hline MK-4 & $13.1 \pm 1.2^{\mathrm{c}}$ & $24.6 \pm 1.0^{\mathrm{b}}$ & $35.6 \pm 2.3^{\mathrm{a}}$ & $19.9 \pm 1.3^{\mathrm{b}}$ & $21.9 \pm 1.0^{\mathrm{b}}$ \\
\hline MK-7 & nd & nd & nd & $192 \pm 24$ & nd \\
\hline \multicolumn{6}{|l|}{ Muscle } \\
\hline PK & nd & $19.4 \pm 1.7$ & nd & nd & nd \\
\hline MK-4 & $5.23 \pm 0.42^{\mathrm{c}}$ & $11.0 \pm 1.0^{\mathrm{b}}$ & $13.7 \pm 1.3^{\mathrm{ab}}$ & $9.95 \pm 0.88^{b}$ & $14.8 \pm 1.1^{\mathrm{a}}$ \\
\hline \multicolumn{6}{|l|}{ Lung } \\
\hline $\mathrm{PK}$ & nd & $39.4 \pm 3.4$ & nd & nd & nd \\
\hline MK-4 & $13.3 \pm 1.0^{\mathrm{b}}$ & $33.9 \pm 2.0^{\mathrm{a}}$ & $34.3 \pm 2.7^{\mathrm{a}}$ & $27.5 \pm 1.8^{\mathrm{a}}$ & $35.5 \pm 2.5^{\mathrm{a}}$ \\
\hline \multicolumn{6}{|c|}{ Adrenal gland } \\
\hline PK & nd & $373 \pm 16$ & nd & nd & nd \\
\hline MK-4 & $62.3 \pm 8.7^{\mathrm{b}}$ & $152 \pm 14^{\mathrm{a}}$ & $156 \pm 15^{\mathrm{a}}$ & $110 \pm 12^{\mathrm{ab}}$ & $150 \pm 9^{a}$ \\
\hline MK-7 & nd & nd & nd & $417 \pm 123$ & nd \\
\hline \multicolumn{6}{|l|}{ Kidney } \\
\hline PK & nd & $28.8 \pm 2.8$ & nd & nd & nd \\
\hline MK-4 & $15.9 \pm 1.3^{\mathrm{c}}$ & $43.0 \pm 1.5^{\mathrm{b}}$ & $24.8 \pm 1.1^{\mathrm{c}}$ & $37.8 \pm 3.1^{\mathrm{b}}$ & $59.7 \pm 3.0^{\mathrm{a}}$ \\
\hline MK-7 & nd & nd & nd & $4.14 \pm 0.57$ & nd \\
\hline \multicolumn{6}{|l|}{ Testis } \\
\hline $\mathrm{PK}$ & nd & $5.84 \pm 0.28$ & nd & nd & nd \\
\hline MK-4 & $62.8 \pm 1.8^{\mathrm{c}}$ & $153 \pm 9^{a b}$ & $62.3 \pm 1.7^{c}$ & $148 \pm 13^{b}$ & $180 \pm 5^{\mathrm{a}}$ \\
\hline \multicolumn{6}{|l|}{ Brain } \\
\hline PK & nd & $6.61 \pm 0.85$ & nd & nd & nd \\
\hline MK-4 & $26.6 \pm 5.3^{c}$ & $53.7 \pm 2.6^{b}$ & $20.5 \pm 0.4^{\mathrm{c}}$ & $52.7 \pm 4.3^{b}$ & $71.9 \pm 3.5^{\mathrm{a}}$ \\
\hline \multicolumn{6}{|l|}{ Tibia } \\
\hline $\mathrm{PK}$ & nd & $55.4 \pm 6.5$ & nd & nd & nd \\
\hline MK-4 & $37.5 \pm 1.0^{\mathrm{c}}$ & $64.7 \pm 3.4^{\mathrm{a}}$ & $50.6 \pm 3.2^{\mathrm{b}}$ & $64.7 \pm 4.8^{\mathrm{a}}$ & $75.6 \pm 1.4^{\mathrm{a}}$ \\
\hline MK-7 & nd & nd & nd & $6.90 \pm 0.41$ & nd \\
\hline
\end{tabular}

Rats were fed a vitamin K-free diet (Free), a diet containing phylloquinone (PK), menaquinone-4 (MK-4), menaquinone-7 (MK-7), or menadione (MD) for $16 \mathrm{wk}$. Vitamin K concentrations were expressed as nmol/L serum or pmol/g tissue. Values are means \pm SE, $n=6$. Labeled means in a row without a common letter differ significantly $(p<0.05)$. nd, not detected. MK-7 was undetectable in the serum, perirenal adipose tissue, heart, muscle, lung, testis, and brain.

MK-7 group was undetectable. MK-7 concentration in the serum and tissues of the Free, PK, MK-4, and MD groups was also undetectable.

MK-4 accumulated in all tissues of the PK, MK-4, MK-7, and MD groups. MK-4 concentration in the serum, liver, adipose tissue, and spleen was higher in the MK-4 group than in the other groups; however, MK-4 concentration in the kidney, testis, tibia, and brain was lower in the MK-4 group than in the PK, MK-7, and MD groups. In particular, MK-4 concentration in the kidney, testis, and brain of the MK-4 group did not differ from that of the Free group.

Effect of orally administered vitamin E on MK-7 and MK-4 concentrations (experiment 2)

The body weight of rats fed a vitamin E- and K-free diet for 3 mo was $307 \pm 3$ g. $\alpha$-Tocopherol concentration in the serum, liver, kidney, heart, and lung was higher in the MK-7E group than in the PK and MK-7 groups at 6 and $24 \mathrm{~h}$ after administration, and its concentration in the testis and brain was higher in the MK-7E group than in the PK and MK-7 groups at $24 \mathrm{~h}$ after administration (Fig. 1). This indicated that $\alpha$-tocopherol contained in 

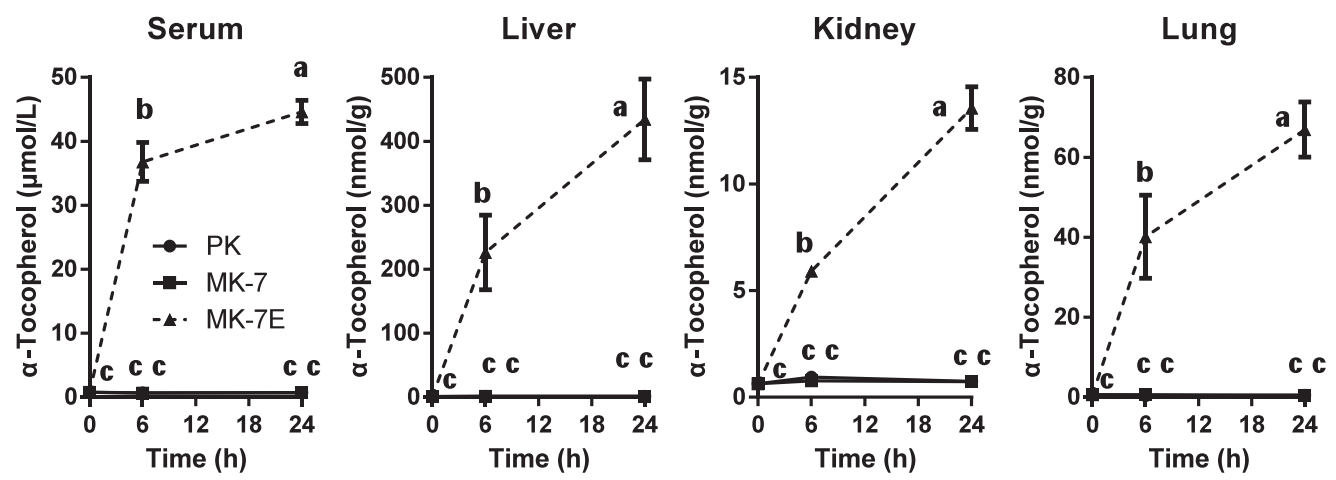

Heart

Testis

\section{Brain}
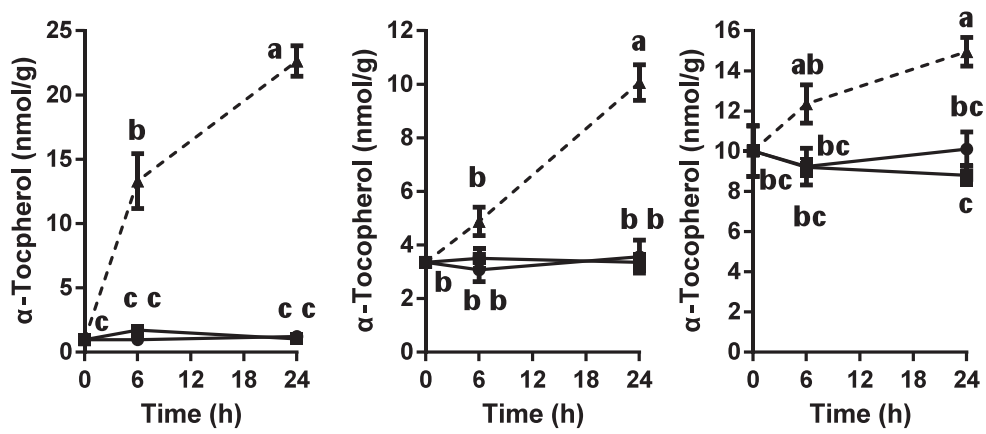

Fig. 1. $\alpha$-Tocopherol concentration in serum and tissues at 0,6 , and $24 \mathrm{~h}$ after oral administration of phylloquinone (PK group), menaquinone-7 (MK-7 group), or menaquinone-7 with $\alpha$-tocopherol (MK-7E group) in experiment 2. Values are means \pm SE, $n=6-8$. Means not sharing a letter differ at $p<0.05$.

the emulsion was successfully absorbed and transferred to the various tissues in the MK-7E group.

PK and MK7 concentrations in the serum and tissues are shown in Fig. 2. The MK-7 concentration in the liver of the MK-7 group at $24 \mathrm{~h}$ increased to $5,640 \pm 1,250 \mathrm{pmol} / \mathrm{g}$. There was no difference between tissue MK-7 concentrations in the MK-7 and MK-7E groups at 6 or $24 \mathrm{~h}$. PK concentration in the serum and tissues of the MK-7 and MK-7E groups and MK-7 concentration in the serum and tissues of the PK group were extremely low or undetectable. These data indicated that MK-7 easily accumulated in the liver and MK-7 concentration in serum and tissues was hardly affected by vitamin $\mathrm{E}$ intake.

Because both PK and MK-7 are thought to be converted to MK-4 in the body, MK-4 concentration in the serum and tissues were measured (Fig. 3). MK-4 concentration in the spleen, kidney, lung, testis, and brain of the PK and MK-7 groups was higher at $24 \mathrm{~h}$ than that at $0 \mathrm{~h}$. There was no difference in MK-4 concentration in the serum, liver, spleen, kidney, adrenal gland, lung, heart, testis, or brain of any group at $24 \mathrm{~h}$ after administration. These data indicated that $\alpha$-tocopherol intake did not affect MK-7 or MK-4 concentration in rats fed MK-7.

\section{DISCUSSION}

The PK content in the diet for the PK group in experiment 1 was $0.75 \mathrm{mg} / \mathrm{kg}$ diet, in accordance with the AIN93-rodent diet (16). The MK-4, MK-7, and MD contents in the diets for the MK-4, MK-7, and MD groups, respectively, were adjusted so that the molar content was equal to the PK content in the diet for the PK group. The total PK content in the AIN93 rodent diet was $0.91 \mathrm{mg} /$ $\mathrm{kg}$ diet, which was the total PK derived from the vitamin mixture ( $0.75 \mathrm{mg} \mathrm{PK} / \mathrm{kg}$ diet, described above) and casein $(0.16 \mathrm{mg} / \mathrm{kg}$ diet) (16). As $\sim 20 \mathrm{~g}$ of diet was consumed per rat per day, daily PK intake from the diet was estimated at $\sim 0.02 \mathrm{mg}$. Thus, the administered PK (0.2 $\mathrm{mg} / \mathrm{rat})$ in experiment 2 was comparable to $\sim 10$ fold the daily PK intake from the diets. The administered MK-7 (0.29 mg/rat) was equivalent to $0.2 \mathrm{mg}$ PK in terms of moles. The administered $\alpha$-tocopherol was calculated similarly. The vitamin E content in the AIN93 rodent diet was $75 \mathrm{IU}$ vitamin $\mathrm{E} / \mathrm{kg}$ diet, which was comparable to the $50 \mathrm{mg} R R R$ - $\alpha$-tocopherol/kg diet (16). As $\sim 20 \mathrm{~g}$ of diet was consumed per rat per day, daily $R R R$ - $\alpha$-tocopherol intake from the diet was estimated at $\sim 1 \mathrm{mg}$. The administered $R R R-\alpha$-tocopherol $(10 \mathrm{mg} /$ rat) was comparable to $\sim 10$-fold the daily $\alpha$-tocopherol intake from the diets.

In experiment 1 , we aimed to use rats to clarify the characteristic of tissue distribution of MK-7 by comparison with the distribution of PK and MK-4. PK accumulated in the serum and all measured tissues of rats fed PK (Table 1). However, MK-7 accumulated mainly in the liver, adrenal gland, and spleen, and it was undetectable in the adipose tissue, heart, muscle, lung, testis, and brain of rats fed MK-7. MK-7 concentration in the liver of the rats fed MK-7 was as high as $801 \pm 57 \mathrm{pmol} / \mathrm{g}$ as compared with $296 \pm 16 \mathrm{pmol} / \mathrm{g}$, which is the hepatic PK concentration in rats fed PK (Table 1). Furthermore, 
Serum PK

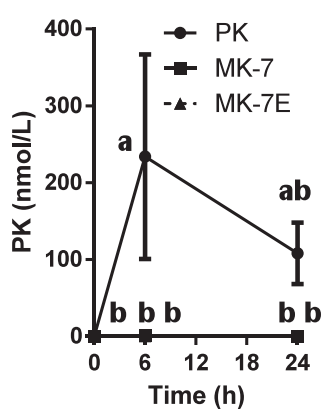

Kidney PK

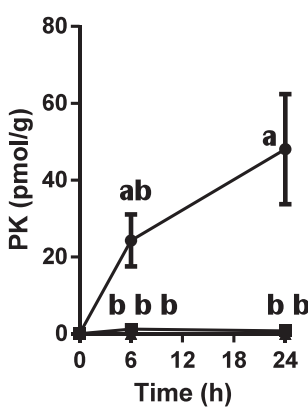

Heart PK

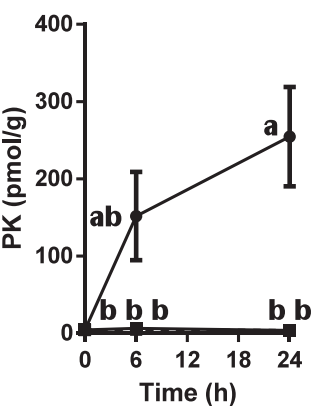

Lung PK

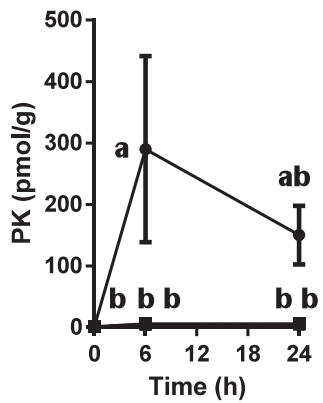

Brain PK

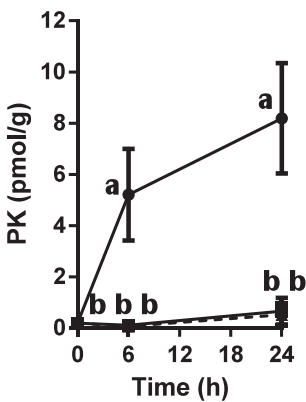

Serum MK-7

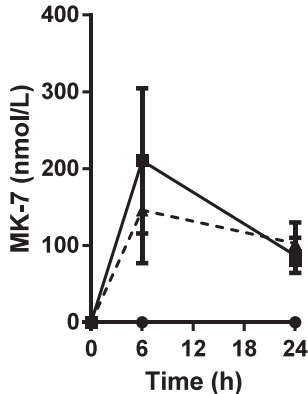

Kidney MK-7

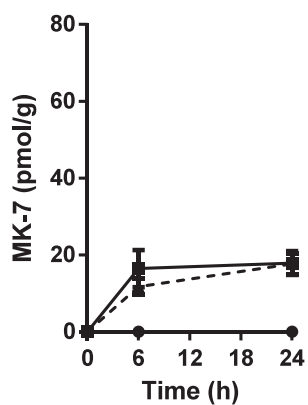

Heart MK-7

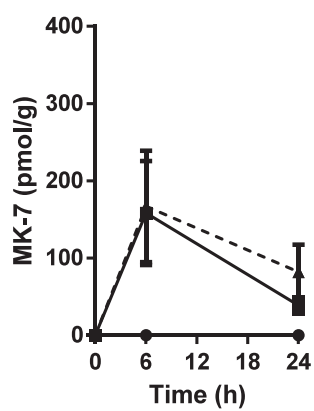

Lung MK-7

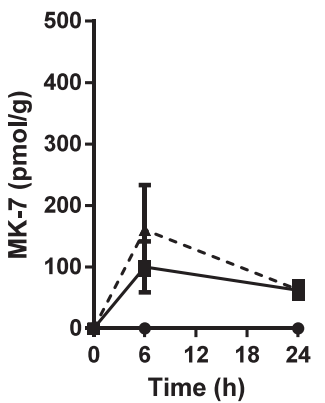

Brain MK-7

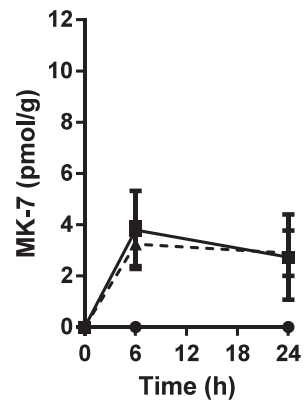

Liver PK

Liver MK-7

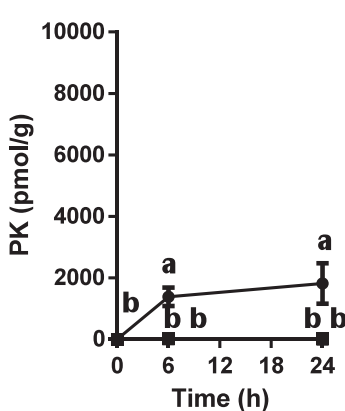

Spleen PK
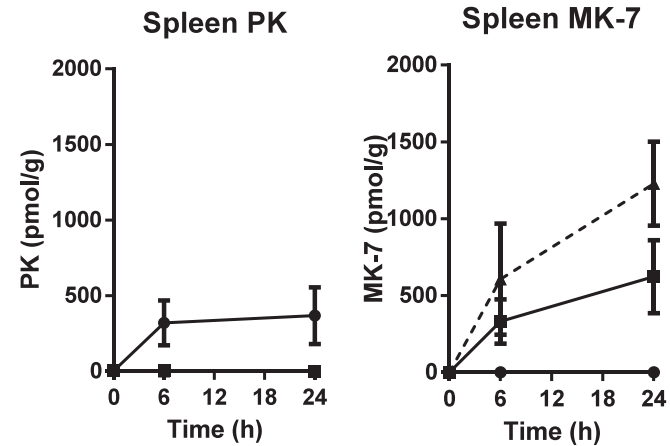

Adrenal PK

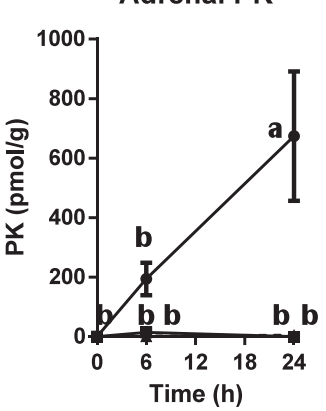

Testis PK
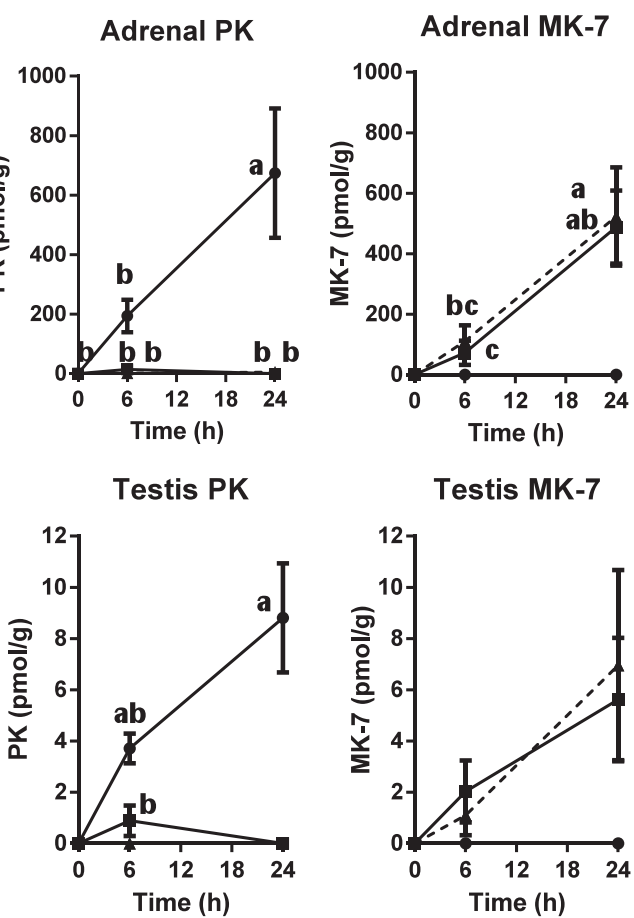

Testis MK-7

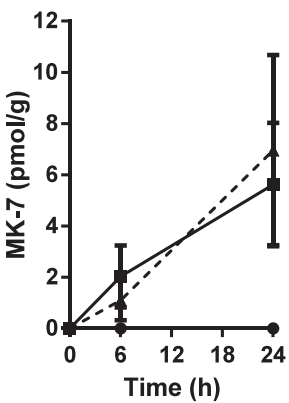

Fig. 2. Phylloquinone (PK) and menaquinone-7 (MK-7) concentrations in serum and tissues at 0, 6, or $24 \mathrm{~h}$ after oral administration of PK (PK group), MK-7 (MK-7 group), or MK-7 with $\alpha$-tocopherol (MK-7E group) in experiment 2. Values are means \pm SE, $n=6-8$. Means not sharing a letter differ at $p<0.05$. MK-7 in the serum and tissues of the PK group was undetectable. 


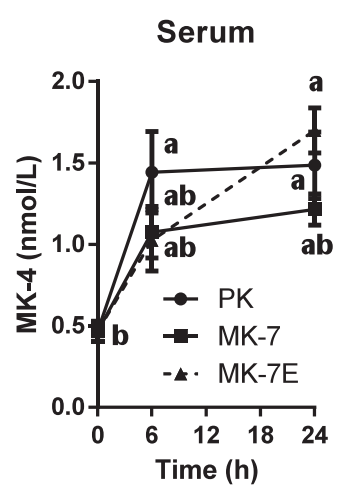

Lung

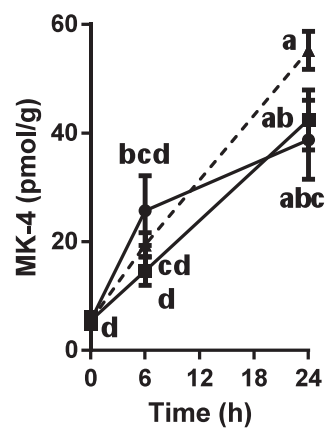

Liver

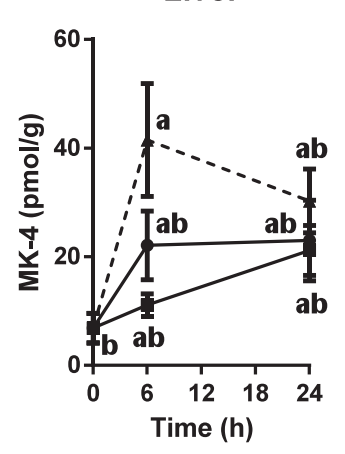

Heart

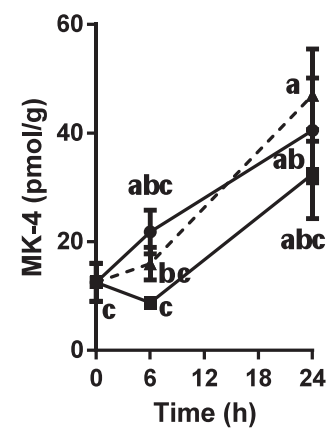

Spleen

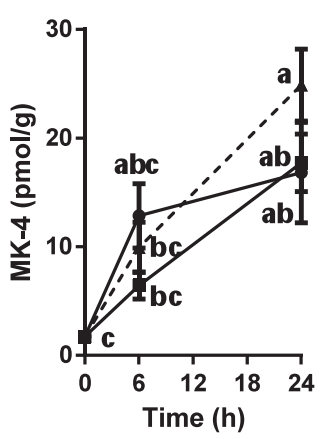

Testis

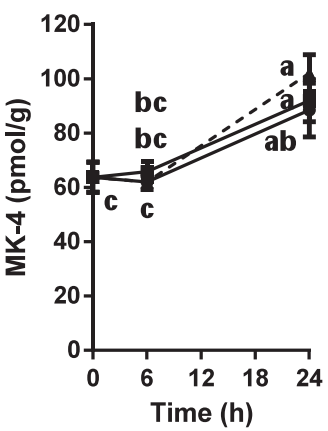

Kidney

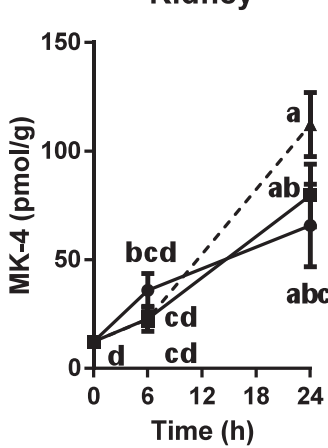

Brain

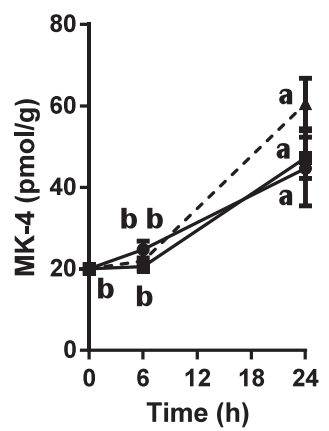

Fig. 3. Menaquinone-4 (MK-4) concentrations in serum and tissues at 0, 6, or $24 \mathrm{~h}$ after oral administration of phylloquinone (PK group), menaquinone-7 (MK-7 group), or menaquinone-7 with $\alpha$-tocopherol (MK-7E group) in experiment 2. Values are means \pm SE, $n=6-8$. Means not sharing a letter differ at $p<0.05$.

in experiment 2, the MK-7 concentration in the liver of MK-7-administered rats after $24 \mathrm{~h}$ was three times higher than the PK concentration in the liver of PKadministered rats after $24 \mathrm{~h}(5,640 \pm 1,250 \mathrm{pmol} / \mathrm{g}$ vs. $1,822 \pm 659 \mathrm{pmol} / \mathrm{g}$, respectively; Fig. 2). PK is incorporated into triacylglycerol-rich chylomicron and VLDL (22). If MK-7 is also transported to various tissues via the liver like the $\mathrm{PK}, \mathrm{MK}-7$ seems to accumulate in the liver at a high concentration because it is more difficult to transport from the liver to peripheral tissues than PK.

Despite the fact that the tissue distribution of MK-7 was different from that of PK as described above, MK-4 concentrations in the serum and all tissues of the MK7-fed and PK-fed rats were equal (Table 1). In MK-7-fed rats, MK-4 accumulated in the adipose tissue, heart, muscle, lung, testis, and brain where MK-7 concentration was below the detection limit. In addition, the increase in MK-4 concentration after oral administration of MK-7 was almost the same as the increase in MK-4 concentration after oral administration of PK (Fig. 3). Hirota et al. recently indicated that a part of dietary PK is cleaved from its side chain in the intestine to become $\mathrm{MD}$, and $\mathrm{MD}$ is further converted to MK-4 by prenylation in the peripheral tissues $(8)$. In experiment 1 , MK-4 concentration in the liver, adipose tissue, heart, spleen, lung, adrenal gland, testis, and tibia of the MDfed rats was the same as that of the PK-fed and MK-7-fed rats, and MK-4 concentration in the muscle, kidney, and brain was even higher in the MD-fed rats than in the PK-fed and MK-7-fed rats (Table 1). This result shows that MD is more easily converted to MK-4 than PK and
MK-7, and this is consistent with the hypothesis that PK and MK-7 are converted to MK-4 via MD. Therefore, a part of ingested MK-7 probably becomes MD in the intestine, is transported to peripheral tissues through a route not involving the liver, and further converted into MK-4 in the peripheral tissues. In addition, because MK-7 was hardly detected in the serum or tissues of vitamin K-deficient, PK-fed, MK-4-fed, and MD-fed rats, the possibility of synthesis of MK-7 from other vitamin $\mathrm{K}$ forms was low.

MK-4 is considered to be the most important vitamin $\mathrm{K}$ because of the conversion of dietary PK and MK-7 into MK-4 in the body and the physiological action of MK-4 but not PK, such as regulation of gene expression in osteoblasts by SXR/PXR activation (23). MK-4 is also used as a therapeutic agent for osteoporosis in Japan, due to its high concentration in blood and its high blood clotting improvement effect (24). However, in experiment 1 , MK-4 concentration in the kidney, testis, tibia, and brain was lower in MK-4-fed rats than in PK-fed, MK-7-fed, and MD-fed rats (Table 1). When physiological action of MK-4 in these tissues is expected by dietary vitamin $\mathrm{K}$, an effective increase in MK-4 concentration can be expected from dietary intake of PK and MK-7 as precursors of MK-4, rather than MK-4 itself.

We have revealed that vitamin E intake lowers PK concentration in extrahepatic tissues of rats (17). Oral administration of $10 \mathrm{mg}$ of $\alpha$-tocopherol lowered the PK concentration in the kidney, adrenal gland, lung, testis, and brain of rats administered $0.2 \mathrm{mg}$ of PK, although MK-4 concentration in the tissues after 
MK-4 administration was not changed by $\alpha$-tocopherol administration (17). In experiment 2, oral administration of $10 \mathrm{mg} \alpha$-tocopherol did not affect the MK-7 or MK-4 concentrations in the serum or tissues after administration of $0.29 \mathrm{mg}$ MK-7 (Figs. 2 and 3). Thus, $\alpha$-tocopherol intake obviously lowered PK concentration in extrahepatic tissues of PK-fed rats but had no effect on MK-4 concentration in MK-4-fed rats or MK-7 concentration in MK-7-fed rats. Moreover, $\alpha$-tocopherol intake had little effect on extrahepatic MK-4 concentration in PK-fed or MK-7-fed rats (17, Figs. 2 and 3). The interference effect of vitamin E on extrahepatic PK concentration was much higher for $\alpha$-tocopherol than $\gamma$-tocopherol $(17,20)$. Because both vitamin E (21) and PK (22) are transported via triacylglycerol-rich lipoprotein, the main reason why vitamin E lowers the PK concentration in extrahepatic tissues may be competitive inhibition of transport of PK from liver to peripheral tissues. That is, $\alpha$-tocopherol, with its high release amount from the liver due to high affinity with $\alpha$-tocopherol transfer protein among vitamin E isoforms (25), inhibits the transport of $\mathrm{PK}$, which is carried through the liver by triacylglycerol-rich VLDL (22). Because MK-7 highly accumulated in the liver and was more difficult to transport from the liver to peripheral tissues than PK (Table 1, Fig. 2), it may be less susceptible to interference by $\alpha$-tocopherol. Much of MK-4 in the tissues of PK-fed or MK-7-fed rats may be derived from MD synthesized probably in the intestine and transported to the tissues without passing through the liver, so the MK-4 concentration is likely to be less susceptible to $\alpha$-tocopherol.

In conclusion, we found that MK-7 was more liable to accumulate in the liver than PK and MK-4, and was difficult to transport to the other tissues except for the spleen and adrenal gland. In addition, $\alpha$-tocopherol did not affect MK-7 or MK-4 concentrations in rats fed MK-7. To clarify the details of MK-7 metabolism, further studies on the mechanisms of absorption of MK-7 in the intestine, secretion of MK-7 from the liver, and catabolism of MK-7 into metabolites in the liver are necessary.

\section{Acknowledgments}

This study was supported in part by JSPS KAKENHI (grant number 17H01970), Japan Society of Nutrition and Food Science, and Research Committee of Fat-Soluble Vitamins. We acknowledge the generous donation of $R R R$ - $\alpha$-tocopherol from Mitsubishi-Chemical Foods Corporation and MK-3 from Eisai Co., Ltd.

\section{REFERENCES}

1) Kamao M, Suhara Y, Tsugawa N, Uwano M, Yamaguchi N, Uenishi K, Ishida H, Sasaki S, Okano T. 2007. Vitamin $\mathrm{K}$ content of foods and dietary vitamin $\mathrm{K}$ intake in Japanese young women. J Nutr Sci Vitaminol 53: 464-470.

2) Thijssen HH, Drittij-Reijnders MJ, Fischer MA. 1996. Phylloquinone and menaquinone- 4 distribution in rats: synthesis rather than uptake determines menaquinone-4 organ concentrations. J Nutr 126: 537-543.

3) Yamamoto R, Komai M, Kojima K, Furukawa Y, Kimura S. 1997. Menaquinone-4 accumulation in various tissues after an oral administration of phylloquinone in
Wistar rats. J Nutr Sci Vitaminol 43: 133-143.

4) Okano T, Shimomura Y, Yamane M, Suhara Y, Kamao M, Sugiura M, Nakagawa K. 2008. Conversion of phylloquinone (vitamin K1) into menaquinone-4 (vitamin K2) in mice: two possible routes for menaquinone-4 accumulation in cerebra of mice. J Biol Chem 283: 11270-11279.

5) Nakagawa K, Hirota Y, Sawada N, Yuge N, Watanabe M, Uchino Y, Okuda N, Shimomura Y, Suhara Y, Okano T. 2010. Identification of UBIAD1 as a novel human menaquinone-4 biosynthetic enzyme. Nature 468: 117-121.

6) Conly JM, Stein K. 1992. The production of menaquinones (vitamin K2) by intestinal bacteria and their role in maintaining coagulation homeostasis. Prog Food Nutr Sci 16: 307-343.

7) Shirakawa H, Komai M, Kimura S. 1990. Antibioticinduced vitamin $\mathrm{K}$ deficiency and the role of the presence of intestinal flora. Int J Vitam Nutr Res 60: 245-251.

8) Hirota Y, Tsugawa N, Nakagawa K, Suhara Y, Tanaka K, Uchino Y, Takeuchi A, Sawada N, Kamao M, Wada A, Okitsu T, Okano T. 2013. Menadione (vitamin K3) is a catabolic product of oral phylloquinone (vitamin K1) in the intestine and a circulating precursor of tissue menaquinone-4 (vitamin K2) in rats. J Biol Chem 288: 33071-33080.

9) American Institute of Nutrition. 1980. Second report of the ad hoc committee for experimental animals. J Nutr 107: 1726.

10) Inaba N, Sato T, Yamashita T. 2015. Low-dose daily intake of vitamin $\mathrm{K}(2)$ (menaquinone-7) improves osteocalcin $\gamma$-carboxylation: a double-blind, randomized controlled trials. J Nutr Sci Vitaminol 61: 471-480.

11) Vossen LM, Schurgers LJ, van Varik BJ, Kietselaer BL, Vermeer C, Meeder JG, Rahel BM, van Cauteren YJ, Hoffland GA, Rennenberg RJ, Reesink KD, de Leeuw PW, Kroon AA. 2015. Menaquinone-7 supplementation to reduce vascular calcification in patients with coronary artery disease: rationale and study protocol (VitaK-CAC Trial). Nutrients 28: 8905-8915.

12) Abdel-Rahman MS, Alkady EA, Ahmed S. 2015. Menaquinone-7 as a novel pharmacological therapy in the treatment of rheumatoid arthritis: A clinical study. Eur J Pharmacol 761: 273-278.

13) Knapen MH, Braam LA, Drummen NE, Bekers O, Hoeks AP, Vermeer C. 2015. Menaquinone-7 supplementation improves arterial stiffness in healthy postmenopausal women. A double-blind randomised clinical trial. Thromb Haemost 113: 1135-1144.

14) Rønn SH, Harsløf T, Pedersen SB, Langdahl BL. 2016. Vitamin K2 (menaquinone-7) prevents age-related deterioration of trabecular bone microarchitecture at the tibia in postmenopausal women. Eur J Endocrinol 175: 541-549.

15) Marles RJ, Roe AL, Oketch-Rabah HA. 2017. US Pharmacopeial Convention safety evaluation of menaquinone-7, a form of vitamin K. Nutr Rev 75: 553-578.

16) Reeves PG, Nielsen FH, Fahey GC Jr. 1993. AIN-93 purified diets for laboratory rodents: final report of the American Institute of Nutrition ad hoc writing committee on the reformulation of the AIN-76A rodent diet. J Nutr 123: 1939-1951.

17) Hanzawa F, Sakuma E, Nomura S, Uchida T, Oda H, Ikeda S. 2014. Excess $\alpha$-tocopherol decreases extrahepatic phylloquinone in phylloquinone-fed rats but not 
menaquinone-4 in menaquinone-4-fed rats. Mol Nutr Food Res 58: 1601-1609.

18) Ikeda S, Nomura S, Hanzawa F, Takahashi S, Oda H, Fujiwara Y, Uchida T. 2018. $\alpha$-Tocopherol intake decreases phylloquinone concentration in bone but does not affect bone metabolism in rats. J Nutr Sci Vitaminol 64: $243-250$.

19) Al Rajabi A, Booth SL, Peterson JW, Choi SW, Suttie JW, Shea MK, Miao B, Grusak MA, Fu X. 2012. Deuteriumlabeled phylloquinone has tissue-specific conversion to menaquinone- 4 among Fischer 344 male rats. J Nutr 142: $841-845$.

20) Hanzawa F, Nomura S, Sakuma E, Uchida T, Ikeda S. 2013. Dietary sesame seed and its lignan, sesamin, increase tocopherol and phylloquinone concentrations in male rats. J Nutr 143: 1067-1073.

21) Abe C, Ikeda S, Uchida T, Yamashita K, Ichikawa T. 2007. Triton WR1339, an inhibitor of lipoprotein lipase, decreases vitamin E concentration in some tissues of rats by inhibiting its transport to liver. J Nutr 137: 345-350.

22) Lamon-Fava S, Sadowski JA, Davidson KW, O’Brien ME, McNamara JR, Schaefer EJ. 1998. Plasma lipoproteins as carriers of phylloquinone (vitamin K1) in humans. Am J Clin Nutr 67: 1226-1231.

23) Ichikawa T, Horie-Inoue K, Ikeda K, Blumberg B, Inoue S. 2006. Steroid and xenobiotic receptor SXR mediates vitamin K2-activated transcription of extracellular matrix-related genes and collagen accumulation in osteoblastic cells. J Biol Chem 281: 16927-16934.

24) Gloor U, Wiss O. 1966. Resorption, retention, excretion and distribution of phylloquinone, menaquinone- 4 and alpha-tocopherolquinone in comparison with alphatocopherol in the rat. Helv Chim Acta 49: 2590-2594.

25) Hosomi A, Arita M, Sato Y, Kiyose C, Ueda T, Igarashi O, Arai H, Inoue K. 1997. Affinity for $\alpha$-tocopherol transfer protein as a determinant of the biological activities of vitamin E analogs. FEBS Lett 409: 105-108. 